\title{
Comparison of the clinicopathological characteristics and prognosis between Chinese patients with breast cancer with bone-only and non-bone-only metastasis
}

\author{
LI ZHANG $^{1 *}$, JIE ZHANG ${ }^{1 *}$, ZHIJUN LI $^{1}$, YANSHENG WU ${ }^{2}$ and ZHONGSHENG TONG ${ }^{1}$ \\ Departments of ${ }^{1}$ Breast Oncology and ${ }^{2}$ Maxillofacial and Otorhinolaryngology Head and Neck Surgery, \\ Tianjin Medical University Cancer Institute and Hospital, National Clinical Research Center for Cancer, Key Laboratory \\ of Cancer Prevention and Therapy, Tianjin's Clinical Research Center for Cancer, Tianjin 300060, P.R. China
}

Received December 13, 2019; Accepted July 1, 2020

DOI: 10.3892/ol.2020.11953

\begin{abstract}
Bone is the most common site of metastatic spread in patients with breast cancer. Patients with bone-only metastasis (BOM) are a unique group. The aim of the present study was to compare the clinicopathological characteristics, survival and prognostic factors of patients with BOM and non-BOM. The clinical data of 1,290 patients with metastatic breast cancer treated at the Tianjin Medical University Cancer Institute and Hospital (Tianjin, China) between January 2008 and December 2017 were reviewed. The clinical data were divided into a BOM group ( $\mathrm{n}=208$ cases) and a non-BOM group ( $n=1,082$ cases). Patients with BOM had longer disease-free survival, progression-free survival (PFS) and overall survival (OS) compared with patients in the non-BOM group. The hormone receptor (HR) status and number of metastases were significant influencing factors of PFS in the BOM group. Furthermore, the HR status, location of bone metastasis and number of bone metastases were significantly associated with OS of patients in the BOM group. Age at diagnosis of metastasis, HR status and tumor stage were significantly associated with OS in the non-BOM group. In the BOM group, patients with $\mathrm{HR}^{+} /$human epidermal growth factor receptor 2 (HER2) tumors had the most favorable prognosis. In the non-BOM group, patients with $\mathrm{HR}^{+} / \mathrm{HER} 2^{-}$and HER $2^{+}$tumors had improved prognosis. In the $\mathrm{BOM}$ with $\mathrm{HR}^{+} / \mathrm{HER} 2$ subgroup, the PFS and OS of patients receiving endocrine therapy or
\end{abstract}

Correspondence to: Dr Zhongsheng Tong, Department of Breast Oncology, Tianjin Medical University Cancer Institute and Hospital, National Clinical Research Center for Cancer, Key Laboratory of Cancer Prevention and Therapy, Tianjin's Clinical Research Center for Cancer, 1 West Huanhu Road, Building B, Tianjin 300060, P.R. China

E-mail: tongzs163@163.com

${ }^{*}$ Contributed equally

Key words: bone metastasis, breast cancer, prognosis, treatment sequential therapy (chemotherapy followed by endocrine therapy) was significantly improved compared with those receiving chemotherapy alone $(\mathrm{P}<0.05)$. Skeletal-related events were significantly associated with the number of bone metastases $(\mathrm{P}<0.001)$. The most common secondary metastatic site in the BOM group was the liver. The prognosis of the patients in the BOM group was improved compared with that in the non-BOM patients. HR ${ }^{-}$and multiple bone metastases, as well as combined axial and appendicular bone metastases, were significantly associated with poor prognosis in the patients with BOM. For patients in the $\mathrm{HR}^{+} / \mathrm{HER} 2^{-}$BOM subgroup, endocrine therapy alone resulted in satisfactory results.

\section{Introduction}

Breast cancer is the most common types of cancer and the second leading cause of cancer-associated death in females worldwide, and accounts for $\sim 500,000$ deaths every year (1). Over $90 \%$ of breast cancer-associated deaths are primarily the result of metastasis (2). Despite recent advances in the diagnosis and treatment, 20-30\% of patients with early-stage breast cancer remain at high risk of recurrence and metastasis (3). The bone has been identified as one of the predominant metastatic sites in patients with breast cancer and bone metastases account for $60-80 \%$ of patients with metastatic breast cancer (MBC) $(4,5)$. Furthermore, the bone is the most common site of initial distant metastatic spread in patients with breast cancer (6). Bone-only metastasis (BOM) is defined as a metastatic disease limited to the bone at the initial diagnosis of MBC. BOM is reported to occur in $25-40 \%$ of patients with MBC $(4,6,7)$. Bone metastases are frequently complicated by skeletal-related events (SREs), including bone pain, pathological fractures, spinal cord compression and hypercalcemia, all of which are associated with a decreased survival time and quality of life (8-10).

Patients with BOM have unique clinical characteristics and prognostic outcomes compared with patients with other types of MBC. Hormone receptor (HR) ${ }^{+}$, human epidermal growth factor receptor 2 (HER2) ${ }^{-}$and a low or intermediate histologic grade preferentially metastasize to the bone rather than the viscera (11-13). Patients with BOM exhibit 
longer survival times compared with patients with visceral metastasis or bone metastases combined with visceral metastases $(13,14)$. Previous studies determined that the median overall survival (OS) of patients with BOM from diagnosis of metastasis was 52-59 months $(7,15,16)$.

Bone metastases from breast cancer are incurable and their clinical management is challenging. Bisphosphonates and denosumab have been used successfully to reduce the frequency of SREs of bone metastasis (17). Regrettably, bisphosphonate treatment is not able prevent the occurrence and development of bone metastasis (18). Palliative radiotherapy is effective in relieving bone pain caused by bone metastasis (19). Endocrine therapy, chemotherapy and sequential therapy (chemotherapy followed by endocrine therapy) may be used as alternative systemic therapies for these patients. However, it remains elusive which treatment method is able to prolong the survival time of patients with BOM the most. In addition, the current knowledge regarding prognostic factors for predicting outcomes among patients with BOM in China is limited.

The aim of the present retrospective study was to compare the clinical characteristics and prognosis between patients with BOM and non-BOM MBC. Outcomes were also compared among patients with different molecular subtypes with BOM or non-BOM. Survival and SREs of patients with BOM and different numbers of bone metastases and first-line treatment approaches were analyzed and the distribution of secondary metastatic sites in patients with BOM was determined. The conclusions of the present study may improve the current understanding of BOM and direct future guidelines for diagnosis and treatment selection. To the best of our knowledge, the present study is so far the largest study based on real-world data comparing the clinicopathological characteristics and prognosis of patients with breast cancer and BOM and non-BOM in China.

\section{Patients and methods}

Patient selection. Patients with MBC treated at Tianjin Medical University Cancer Institute and Hospital (Tianjin, China) between January 2008 and December 2017 were retrospectively analyzed. All patients were assigned to either the BOM or non-BOM group. Patients with the bone as the first and only site of metastasis at the time of $\mathrm{MBC}$ diagnosis were assigned to the BOM group. Patients with non-skeletal metastases (including non-skeletal combined with bone metastases) at the time of MBC diagnosis were assigned to the non-BOM group. A total of 1,290 patients were diagnosed with $\mathrm{MBC}$; $208(16.1 \%)$ had BOM and 1,082 (83.9\%) had non-skeletal metastasis. Patients were required to have at least 6 months of follow-up. The median follow-up period was 26 months.

The inclusion criteria were as follows: i) Primary unilateral breast cancer that was pathologically diagnosed; ii) female patients; iii) metastatic disease pathologically diagnosed or diagnosed using an imaging technique [e.g. bone scan, CT, MRI or positron emission tomography (PET)/CT]; and iv) relatively complete clinicopathological data and survival data. The exclusion criteria were as follows: i) Primary bilateral breast cancer; ii) male patients; iii) early breast cancer; iv) coexistence of another malignancy; or iv) patients with incomplete data. The present study was performed in accordance with all relevant guidelines, and the procedures were approved by the Tianjin
Medical University Ethical Committee (Tianjin, China). The requirement of informed consent was waived due to the retrospective study design.

Tumor subtype assessment and evaluation. To diagnose patients with metastatic disease, all patients included in the present study were examined using a whole-body imaging technique (e.g. B-ultrasound, CT, MRI or PET). Patients with a single bone metastasis were diagnosed by bone biopsy. Tumor types were classified as infiltrating ductal carcinoma or others. The clinical stages were classified according to the American Joint Committee on Cancer TNM staging system 7th edition (20). The expression status of progesterone receptor (PR), estrogen receptor (ER) and HER2 was assessed by initial immunohistochemical (IHC) analysis of a biopsy of the breast carcinoma. Breast cancer was divided into three major molecular subtypes: $\mathrm{HR}^{+} / \mathrm{HER} 2^{-}$, $\mathrm{HER}^{+}$and $\mathrm{HR}^{-} / \mathrm{HER} 2^{-}$. $\mathrm{HR}^{+}$ was defined as ER or PR $\geq 1 \%$ by IHC (20). Regarding HER2, IHC 1+ was considered as negative and IHC 3+ was considered as positive, while IHC 2+ was inconclusive and fluorescence in situ hybridization (FISH) was used to make a decision (21). In the case of discordance between IHC and FISH results, the FISH result was prioritized. All other samples were classified as negative on analysis. In addition, triple-negative breast cancer (TNBC) was negative for HR and HER2.

Bone metastasis characteristics. The location of bone metastasis was determined by examining clinical records and imaging reports at the time of BOM diagnosis. Skull, sternum, rib, spine and pelvic bones were classified as axial bones. Forearm, arms, hands, thighs, shanks and foot bones were classified as appendicular bones. Single bone metastasis was defined as a solitary metastatic lesion confined to a single bone. Multiple bone metastases were defined as $\geq 2$ lesions, including $>1$ lesion in the same bone. Bone metastasis is incurable; it is almost impossible to remove tumors in a metastasized bone and then tumors tend to recur or metastasize to other organs (22). The metastasis-free interval (MFI) was defined as the interval between the first diagnosis of BOM and time of the second presentation with metastatic disease.

Treatment modalities. Data on first-line treatment characteristics for 144 patients with $\mathrm{BOM}$ and $\mathrm{HR}^{+} / \mathrm{HER} 2^{-}$status, including administration of chemotherapy, endocrine therapy or sequential therapy (chemotherapy followed by endocrine therapy), were obtained. A total of 36 patients received chemotherapy, 33 endocrine therapy and 75 sequential therapy.

Statistical analysis. Categorical variables used to quantify clinical characteristics are presented as frequencies and proportions. The mean and a Student's t-test were used to compare the age differences between the BOM and non-BOM groups. Pearson's $\chi^{2}$ tests and Fisher's exact tests were used to compare the differences between two groups. The primary endpoints of the present study were disease-free survival (DFS), progression-free survival (PFS) and OS from the time-point of diagnosis of BOM. DFS was defined as the time interval from the diagnosis of breast cancer to recurrence or metastasis. PFS was defined as the time interval from diagnosis of metastasis to progression, death or the last follow-up date, whichever occurred 
Table I. Patient characteristics at the initial diagnosis of breast cancer in the BOM $(n=208)$ and non-BOM $(n=1,082)$ groups

\begin{tabular}{|c|c|c|c|}
\hline Characteristic & BOM group & non-BOM group & P-value \\
\hline Median age at primary diagnosis (range), years & $48(24-72)$ & $48(21-78)$ & 0.978 \\
\hline Median age at metastasis or recurrence (range), years & $50(24-78)$ & $52(25-80)$ & 0.262 \\
\hline Menopausal status, n (\%) & & & 0.062 \\
\hline Premenopause & $116(55.8)$ & $527(48.7)$ & \\
\hline Postmenopause & $92(44.2)$ & $555(51.3)$ & \\
\hline Lymph node status, n (\%) & & & 0.838 \\
\hline Negative & $61(29.3)$ & $325(30.0)$ & \\
\hline Positive & $147(70.7)$ & $757(70.0)$ & \\
\hline Tumor stage, n (\%) & & & 0.392 \\
\hline $\mathrm{T} 1$ & $53(25.5)$ & $329(30.4)$ & \\
\hline $\mathrm{T} 2$ & $103(49.5)$ & $515(47.6)$ & \\
\hline $\mathrm{T} 3$ & $34(16.3)$ & $141(13.0)$ & \\
\hline $\mathrm{T} 4$ & $18 \quad(8.7)$ & $97 \quad(9.0)$ & \\
\hline Clinical stage, n (\%) & & & $<0.001$ \\
\hline I & $24(11.5)$ & $151(14.0)$ & \\
\hline II & $75(36.1)$ & $447(41.3)$ & \\
\hline III & $61(29.3)$ & $382(35.3)$ & \\
\hline IV & $48(23.1)$ & $102(9.4)$ & \\
\hline Tumor type, n (\%) & & & 0.273 \\
\hline Invasive ductal carcinoma & $170(81.7)$ & $917(84.8)$ & \\
\hline Others & $38(18.3)$ & $165(15.2)$ & \\
\hline HR status, n (\%) & & & $<0.001$ \\
\hline Negative & $39(18.7)$ & $422(39.0)$ & \\
\hline Positive & $169(81.3)$ & $660(61.0)$ & \\
\hline \multicolumn{4}{|l|}{ HER2 status, n (\%) } \\
\hline Negative & $171(82.2)$ & $814(75.2)$ & 0.030 \\
\hline Positive & $37(17.8)$ & $268(24.8)$ & \\
\hline Molecular type, n (\%) & & & $<0.001$ \\
\hline $\mathrm{HR}^{+} / \mathrm{HER} 2^{-}$ & $144(69.2)$ & $538(49.7)$ & \\
\hline 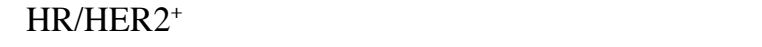 & $40(19.3)$ & $268(24.8)$ & \\
\hline $\mathrm{HR}^{-} / \mathrm{HER} 2^{-}$ & $24(11.5)$ & $276(25.5)$ & \\
\hline
\end{tabular}

HER2, human epidermal growth factor receptor 2; HR, hormone receptor; BOM, bone-only metastases.

first. OS was defined as the time interval from diagnosis of metastasis to death or to the last follow-up date if patients were alive, whichever occurred first. DFS, PFS and OS curves were drawn using the Kaplan-Meier method and compared among groups using a log-rank test. Univariate analysis was performed by logistic regression. Cox proportional hazards model was used for multivariate analysis and to estimate the hazard ratio and $95 \%$ CIs. All statistical tests used were two-sided. $\mathrm{P}<0.05$ was considered to indicate a statistically significant difference. SPSS version 25.0 (IBM Corp.) and GraphPad Prism version 7 were used to analyze the data.

\section{Results}

Patient characteristics. The median age at breast cancer diagnosis in the BOM and non-BOM groups was 48 years (range, 24-72 and 21-78 years, respectively). The median ages at $\mathrm{MBC}$ diagnosis in the BOM and non-BOM groups were 50 years (range, 24-78 years) and 52 years (range, 25-80 years), respectively. The clinical and pathological characteristics of the patients in the two groups are presented in Table I. In total, 1,290 patients with MBC were enrolled in the present study, including $208(16.1 \%)$ patients in the BOM group and $1,082(83.9 \%)$ patients in the non-BOM group. Compared with the non-BOM group, patients with BOM were more frequently diagnosed as clinical stage IV in the first instance $(\mathrm{P}<0.001)$, as well as $\mathrm{HR}^{+}(\mathrm{P}<0.001)$ and HER2- $(\mathrm{P}=0.03)$. The metastatic lesions in non-BOM patients included the lungs $(60.7 \%)$, liver $(42.4 \%)$ and brain $(4.6 \%)$.

The survival time of patients with BOM was longer than that of patients with non-BOM (Fig. 1). The median DFS time of patients with BOM was 31 months, while that of patients with 
A

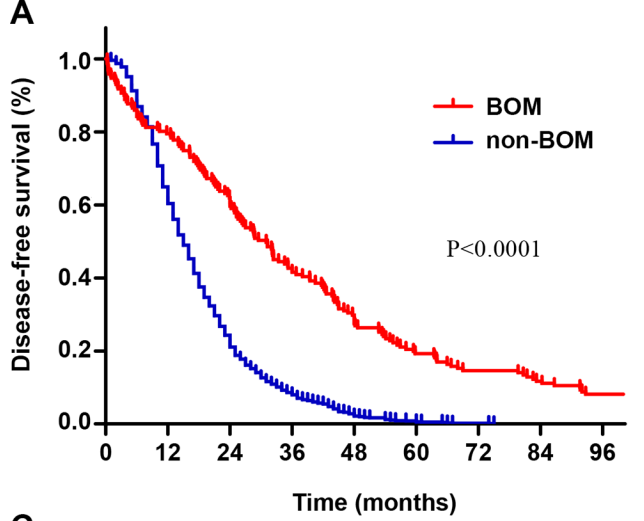

C

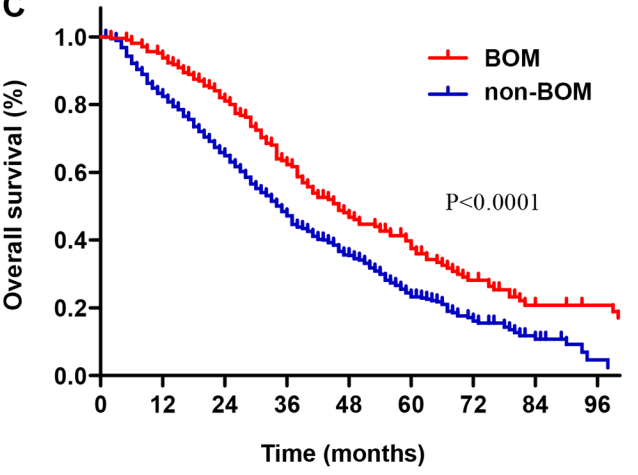

B

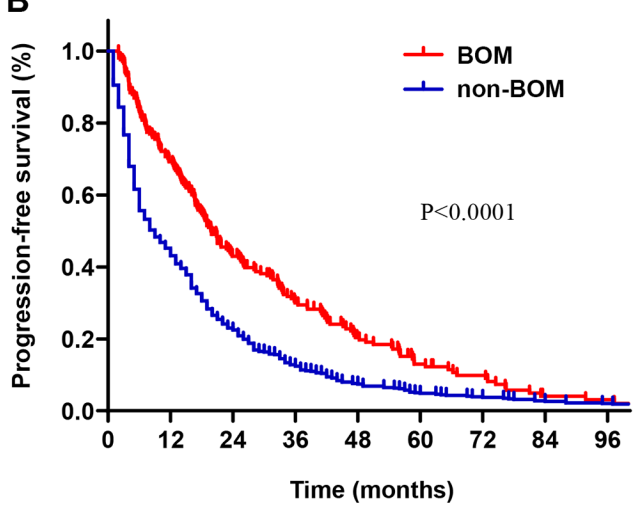

Figure 1. (A) Disease-free survival, (B) progression-free survival and (C) overall survival curves of patients in the BOM and non-BOM groups. BOM, bone-only metastasis.

non-BOM was 15 months $(\mathrm{P}<0.001$; Fig. 1A). The median PFS in patients with BOM and non-BOM was 19.9 and 9.0 months, respectively $(\mathrm{P}<0.001$; Fig. 1B). The median OS in the BOM and non-BOM groups was 45 months (95\% CI: 38.1-51.9) and 35 months (95\% CI:32.7-37.2), respectively ( $\mathrm{P}<0.001$; Fig. 1C).

Prognostic factors for patients with BOM. Univariate analyses indicated that the tumor stage, HR status, HER2 status, molecular subtypes and the number of bone metastases were associated with PFS ( $\mathrm{P}<0.05$; Table II). HR status, molecular subtypes, location of bone metastasis and the number of bone metastases were associated with OS $(\mathrm{P}<0.05$; Table II). Additionally, bisphosphonates therapy and radiotherapy were not associated with PFS or OS in patients with BOM.

Multivariate analysis using Cox regression indicated that the HR status and the number of bone metastases were independent factors affecting the PFS of patients with BOM. HR ${ }^{-}$and multiple bone metastases were significantly associated with shorter PFS of patients with BOM (Table III). HR status, the number of bone metastases and location of bone metastases were independent factors affecting OS of patients with BOM. $\mathrm{HR}^{-}$, multiple bone metastases, as well as the combination of axial and appendicular bone metastases, were significantly associated with shorter OS of patients with BOM (Table IV).

Prognostic factors for non-BOM patients. Univariate analysis indicated that age at diagnosis of metastasis, tumor stage, HR status and molecular subtypes were associated with OS of non-BOM patients $(\mathrm{P}<0.05$; Table $\mathrm{V})$. In the multivariate analysis, age at diagnosis of metastasis, HR status and tumor stage were independent factors affecting the OS of non-BOM patients (Table VI). In non-BOM patients, $\mathrm{HR}^{-}$, age $\leq 35$ years at diagnosis of metastasis or stage T3-4 were associated with poor prognosis.

Survival analysis of patients with BOM and non-BOM with different molecular subtypes. Survival analyses of patients with BOM with different molecular subtypes indicated that compared with patients with HER $2^{+}$or HR $/ \mathrm{HER} 2^{-}$, those with $\mathrm{HR}^{+} / \mathrm{HER} 2^{-}$had significantly improved DFS, PFS and OS. There was no significant difference in DFS, PFS or OS between patients with HER $2^{+}$and HR/HER $2^{-}(\mathrm{P}=0.25,0.83$ and 0.25 , respectively; Fig. 2A-C).

Survival analyses of non-BOM patients with different molecular subtypes suggested that patients with $\mathrm{HR}^{+} / \mathrm{HER} 2$ and HER $2^{+}$had significantly longer PFS and OS compared with those with $\mathrm{HR}^{-} / \mathrm{HER} 2$. There was no significant difference in PFS or OS of patients with HER2 ${ }^{+}$and $\mathrm{HR}^{+} / \mathrm{HER} 2^{-}(\mathrm{P}=0.12$ and $\mathrm{P}=0.28$, respectively). Patients with $\mathrm{HR}^{+} / \mathrm{HER} 2^{-}$had significantly longer DFS compared with patients with HER2 ${ }^{+}$ or HR/HER2 ${ }^{-}$. There was no significant difference in the DFS of patients with HER2 ${ }^{+}$and HR-/HER2- ( $\mathrm{P}=0.61$; Fig. 2D-F).

Treatment outcomes. First-line treatment approaches for patients with BOM and $\mathrm{HR}^{+} / \mathrm{HER} 2^{-}$status included chemotherapy, endocrine therapy and sequential therapy. Of the total 144 patients with $\mathrm{HR}^{+} / \mathrm{HER} 2^{-} \mathrm{BOM}, 36$ received chemotherapy, 33 received endocrine therapy and 75 received sequential therapy. The proportion of patients receiving taxane or anthracyclines was $91.7 \%$ (33/36) in the chemotherapy group and $96 \%$ (72/75) in the sequential therapy group. Among patients receiving endocrine or sequential therapy, the proportions of 
Table II. Univariate analyses of the influence of clinical factors on the PFS and OS of patients with BOM.

\begin{tabular}{|c|c|c|c|c|c|c|c|}
\hline \multirow[b]{2}{*}{ Characteristic } & \multirow[b]{2}{*}{ Number } & \multicolumn{2}{|c|}{ PFS, $\%$} & \multirow[b]{2}{*}{ P-value } & \multicolumn{2}{|c|}{ OS, $\%$} & \multirow[b]{2}{*}{ P-value } \\
\hline & & 3 years & 5 years & & 3 years & 5 years & \\
\hline Age at primary diagnosis, years & & & & 0.246 & & & 0.244 \\
\hline$<35$ & 25 & 14.4 & 4.8 & & 49.9 & 21.8 & \\
\hline $35-60$ & 153 & 31.9 & 14.7 & & 64.4 & 41.3 & \\
\hline$\geq 60$ & 30 & 29.2 & 7.8 & & 56.6 & 38.2 & \\
\hline Menopausal status at primary diagnosis & & & & 0.879 & & & 0.740 \\
\hline Premenopause & 116 & 27.1 & 12.9 & & 59.0 & 33.6 & \\
\hline Postmenopause & 92 & 32.6 & 11.0 & & 65.2 & 46.2 & \\
\hline Lymph node status at primary diagnosis & & & & 0.412 & & & 0.785 \\
\hline Negative & 61 & 31.7 & 16.4 & & 69.2 & 41.4 & \\
\hline Positive & 147 & 29.2 & 11.3 & & 59.1 & 37.7 & \\
\hline Tumor stage at primary diagnosis & & & & 0.040 & & & 0.114 \\
\hline $\mathrm{T} 1$ & 53 & 43.7 & 20.7 & & 67.4 & 50.3 & \\
\hline $\mathrm{T} 2$ & 103 & 20.6 & 13.2 & & 59.6 & 37.0 & \\
\hline $\mathrm{T} 3$ & 34 & 28.4 & 11.8 & & 61.3 & 29.6 & \\
\hline $\mathrm{T} 4$ & 18 & 39.9 & 0 & & 62.2 & 23.3 & \\
\hline Clinical stage at primary diagnosis & & & & 0.337 & & & 0.476 \\
\hline I & 24 & 39.4 & 24.6 & & 72.2 & 49.4 & \\
\hline II & 75 & 23.7 & 17.9 & & 66.5 & 37.7 & \\
\hline III & 61 & 28.3 & 7.7 & & 51.5 & 34.1 & \\
\hline IV & 48 & 37.0 & 5.9 & & 64.1 & 37.6 & \\
\hline Pathologic type at primary diagnosis & & & & 0.118 & & & 0.149 \\
\hline Invasive ductal carcinoma & 170 & 27.7 & 12.3 & & 59.2 & 37.3 & \\
\hline Others & 38 & 40.4 & 15.9 & & 75.3 & 49.6 & \\
\hline HR status at primary diagnosis & & & & $<0.001$ & & & $<0.001$ \\
\hline Negative & 39 & 9.6 & 4.8 & & 30.5 & 13.1 & \\
\hline Positive & 169 & 34.7 & 14.9 & & 69.3 & 45.3 & \\
\hline HER2 status at primary diagnosis & & & & 0.032 & & & 0.168 \\
\hline Negative & 171 & 32.3 & 13.5 & & 66.5 & 42.4 & \\
\hline Positive & 37 & 19.5 & 10.4 & & 40.0 & 25.4 & \\
\hline Molecular subtype at primary diagnosis & & & & 0.001 & & & $<0.001$ \\
\hline $\mathrm{HR}^{+} / \mathrm{HER} 2^{-}$ & 144 & 36.0 & 14.9 & & 71.9 & 45.4 & \\
\hline HR/HER $2^{+}$ & 40 & 20.4 & 12.8 & & 42.8 & 26.4 & \\
\hline $\mathrm{HR}^{-} / \mathrm{HER} 2^{-}$ & 24 & 10.0 & 0 & & 33.5 & 16.8 & \\
\hline Bone radiotherapy & & & & 0.977 & & & 0.353 \\
\hline No & 131 & 29.3 & 12.4 & & 59.2 & 36.3 & \\
\hline Yes & 77 & 30.4 & 13.6 & & 66.7 & 42.3 & \\
\hline Bisphosphonate therapy & & & & 0.967 & & & 0.386 \\
\hline No & 23 & 30.4 & 13.0 & & 51.1 & 33.7 & \\
\hline Yes & 185 & 30.0 & 13.0 & & 63.0 & 40.2 & \\
\hline Location of bone metastases at $\mathrm{BOM}$ diagnosis & & & & 0.123 & & & 0.003 \\
\hline Axial & 164 & 28.1 & 11.8 & & 63.4 & 40.1 & \\
\hline Appendicular & 7 & 71.4 & 53.6 & & 85.7 & 71.4 & \\
\hline Axial and appendicular & 37 & 30.4 & 9.1 & & 48.7 & 24.7 & \\
\hline Number of bone metastases at BOM diagnosis & & & & 0.035 & & & 0.004 \\
\hline Single & 60 & 43.7 & 17.5 & & 77.0 & 51.7 & \\
\hline Multiple & 148 & 24.4 & 11.2 & & 56.1 & 33.3 & \\
\hline
\end{tabular}

HER2, human epidermal growth factor receptor 2; HR, hormone receptor; PFS, progression-free survival; OS, overall survival; BOM, bone-only metastasis. 
Table III. Multivariate analysis of prognostic factors affecting progression-free survival of patients with BOM.

\begin{tabular}{lcc}
\hline Variable & Hazard ratio & 95\% CI \\
\hline HR status at breast cancer diagnosis & & Reference \\
Negative & 1.00 & $0.40-0.92$ \\
Positive & 0.63 & 0.027 \\
Number of bone metastases at BOM diagnosis & 1.00 & Reference \\
Multiple & 0.64 & $0.45-0.91$ \\
Single & & - \\
\hline The factors with P<0.05 in the univariate analysis in Table II were incorporated in the multivariate analysis. Tumor stage, HER2 status and \\
molecular subtype at primary diagnosis were adjusted for. HR, hormone receptor; BOM, bone-only metastasis.
\end{tabular}

Table IV. Multivariate analysis of prognostic factors affecting overall survival of patients with BOM.

\begin{tabular}{lcc}
\hline Variable & Hazard ratio & 95\% CI \\
\hline HR status at breast cancer diagnosis & & Reference \\
Negative & 1.00 & $0.32-0.90$ \\
Positive & 0.54 & 0.020 \\
Number of metastases at BOM diagnosis & & Reference \\
Multiple & 1.00 & $0.40-0.96$ \\
Single & 0.62 & 0.031 \\
Location of bone metastasis at BOM diagnosis & & Reference \\
Axial and appendicular & 1.00 & $0.41-1.02$ \\
Axial & 0.65 & $0.01-0.57$ \\
Appendicular & 0.07 & 0.062 \\
\hline
\end{tabular}

The factors with $\mathrm{P}<0.05$ in the univariate analysis in Table II were incorporated into the multivariate analysis. Molecular subtype was adjusted for. BOM, bone-only metastases; HR, hormone receptor.

those receiving aromatase inhibitors was $63.4 \%(21 / 33)$ and $78.7 \%(59 / 75)$, the proportions of those receiving tamoxifen was $15.2 \%(5 / 33)$ and $8 \%(6 / 75)$, the proportions of those receiving fulvestrant was $12.1 \%(4 / 33)$ and $13.3 \%(10 / 75)$, and the proportions of those receiving palbociclib were $9.1 \%(3 / 33)$ and $0 \%$. Premenopausal patients with endocrine therapy were all treated by ovarian function suppression. It is important to note that Chinese patients have different national conditions and medical policies to face. The medical insurance coverage rate in China is $97.5 \%$, but patients have varying medical expenses according to different types of insurance (23). Palbociclib was approved by the Chinese Food and Drug Administration on July 31, 2018 (24); despite its approval, the high medical costs have limited its use in China. Only a small number of patients in the present study received palbociclib due to its late availability and high medical costs. Most patients preferred chemotherapy because it was relatively cheaper and was covered by health insurance. Table VII presents the different treatments applied for patients with $\mathrm{HR}^{+} / \mathrm{HER} 2^{-} \mathrm{BOM}$ with different characteristics at diagnosis of metastasis. Patients with multiple bone metastases were more likely to receive sequential therapy $(\mathrm{P}<0.001)$.

Among the patients with $\mathrm{HR}^{+} / \mathrm{HER} 2^{-}$tumors, those who received sequential therapy or endocrine therapy had longer
PFS and OS compared with those who received chemotherapy. There was no significant difference in the survival of patients who received sequential therapy and endocrine therapy $(\mathrm{P}=0.53$ and 0.48 , respectively; Fig. 3$)$. Among the patients with a single bone metastasis, patients who received endocrine therapy and sequential therapy had longer PFS and OS compared with those who received chemotherapy. There was no significant difference in PFS or OS between sequential therapy and endocrine therapy $(\mathrm{P}=0.28$ and 0.12 , respectively; Fig. 4). Among the patients with multiple bone metastases, patients who received endocrine therapy or sequential therapy had longer PFS and OS compared with those who received chemotherapy. There was no difference in PFS and OS between sequential therapy and endocrine therapy $(\mathrm{P}=0.43$ and 0.33, respectively; Fig. 5).

Association between SREs and characteristics of bone metastases. Of the 208 patients with BOM, 131 (63\%) were complicated by SREs; SREs were significantly associated with the number of bone metastases $(\mathrm{P}<0.001$; Table VIII). The incidence of SREs in patients with multiple bone metastases was significantly higher compared with that in patients with a single bone metastasis. The location of bone metastasis 
Table V. Univariate analyses of prognostic factors affecting overall survival of patients with non-bone-only metastasis.

\begin{tabular}{|c|c|c|c|c|}
\hline \multirow[b]{2}{*}{ Characteristic } & \multirow[b]{2}{*}{$\mathrm{N}(\%)$} & \multicolumn{2}{|c|}{ Overall survival, $\%$} & \multirow[b]{2}{*}{ P-value } \\
\hline & & 3 years & 5 years & \\
\hline Age at diagnosis of metastasis, years & & & & 0.008 \\
\hline$\leq 35$ & $85 \quad(7.9)$ & 36.0 & 8.0 & \\
\hline$>35$ & $997(92.1)$ & 48.1 & 23.9 & \\
\hline Lymph node status & & & & 0.077 \\
\hline Negative & $325(30.0)$ & 50.7 & 26.4 & \\
\hline Positive & $757(70.0)$ & 45.5 & 21.7 & \\
\hline Tumor stage & & & & 0.007 \\
\hline $\mathrm{T} 1-2$ & $844(78.0)$ & 48.8 & 25.1 & \\
\hline $\mathrm{T} 3-4$ & $238(22.0)$ & 41.0 & 15.5 & \\
\hline Clinical stage & & & & 0.205 \\
\hline I & $151(14.0)$ & 49.4 & 26.1 & \\
\hline II & $447(41.3)$ & 49.6 & 25.7 & \\
\hline III & $382(35.3)$ & 44.1 & 19.2 & \\
\hline IV & $102(9.4)$ & 42.1 & 14.1 & \\
\hline Pathologic type & & & & 0.437 \\
\hline Invasive ductal carcinoma & $909(84.0)$ & 45.7 & 24.6 & \\
\hline Others & $173(16.0)$ & 54.3 & 18.6 & \\
\hline HR status & & & & $<0.001$ \\
\hline Negative & $422(39.0)$ & 36.4 & 15.4 & \\
\hline Positive & $660(61.0)$ & 54.3 & 28.6 & \\
\hline HER2 status & & & & 0.943 \\
\hline Negative & $814(75.2)$ & 47.5 & 23.2 & \\
\hline Positive & $268(24.8)$ & 46.2 & 23.6 & \\
\hline Molecular subtype & & & & $<0.001$ \\
\hline $\mathrm{HR}^{+} / \mathrm{HER} 2^{-}$ & $538(49.7)$ & 54.2 & 28.0 & \\
\hline HR/HER2 ${ }^{+}$ & $268(24.8)$ & 46.2 & 23.6 & \\
\hline $\mathrm{HR}^{-} / \mathrm{HER} 2^{-}$ & $276(25.5)$ & 34.5 & 14.7 & \\
\hline
\end{tabular}

HR, hormone receptor; HER2, human epidermal growth factor receptor 2.

Table VI. Multivariate analysis of overall survival of patients with non-bone-only metastasis.

\begin{tabular}{lccr}
\hline Variable & Hazard ratio & $95 \%$ CI & P-value \\
\hline Age at recurrence or metastasis ( $\leq 35$ vs. $>$ 35 years) & 1.36 & $1.03-1.79$ & 0.027 \\
HR status (negative vs. positive) & 1.55 & $1.32-0.81$ & 0.027 \\
Tumor stage (T3-4 vs. T1-2) & 1.21 & $1.00-1.46$ & 0.048 \\
\hline
\end{tabular}

The factors with $\mathrm{P}<0.05$ in the univariate analysis in Table $\mathrm{V}$ were incorporated into the multivariate analysis. Molecular subtype was adjusted for. HR, hormone receptor.

had no impact on the incidence of SREs. For patients with $\mathrm{HR}^{+} / \mathrm{HER} 2^{-}$tumors, there was no significant difference in the incidence of SREs among the different treatments.

Distribution of the secondary distant metastatic site. Of the 208 patients with BOM, 109 (52.4\%) developed a secondary distant metastasis and the median MFI was 21 months (95\% CI: 17.2-24.8 months). Furthermore, of the 109 patients with a second distant metastasis, $25.7 \%$ had an MFI within 1 year and $56.0 \%$ had an MFI within 2 years. The most common metastatic site was the liver (51.4\%), followed by the lung $(30.3 \%)$ and brain $(13.8 \%)$. The proportions of $\mathrm{HR}^{+} / \mathrm{HER} 2^{-}$and HER2 ${ }^{+}$ 
A

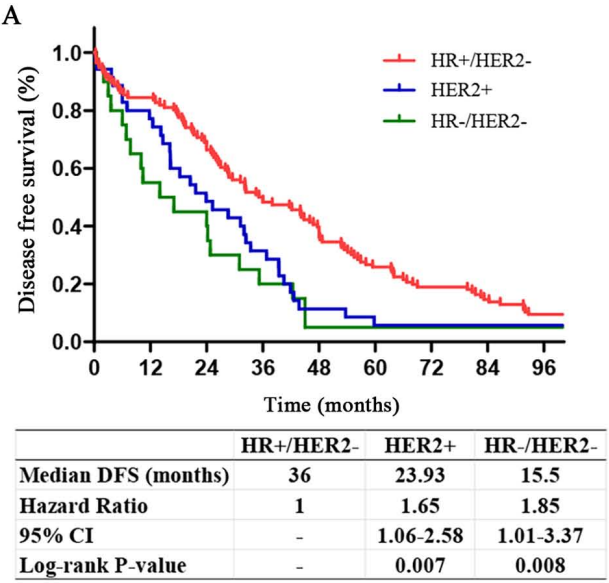

$\mathrm{C}$

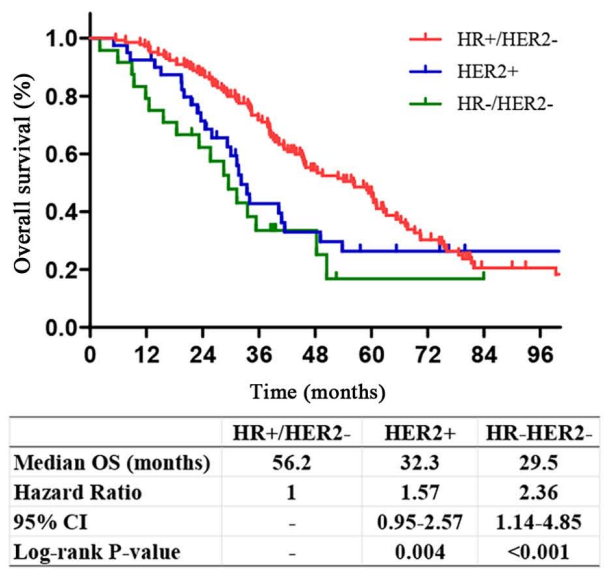

$\mathrm{E}$

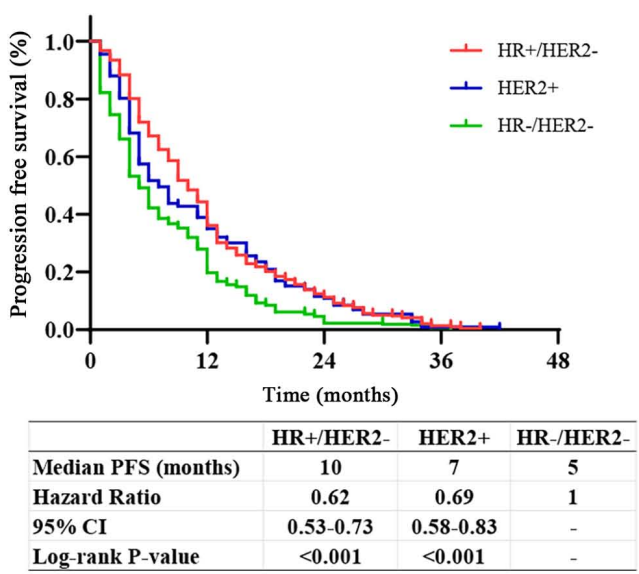

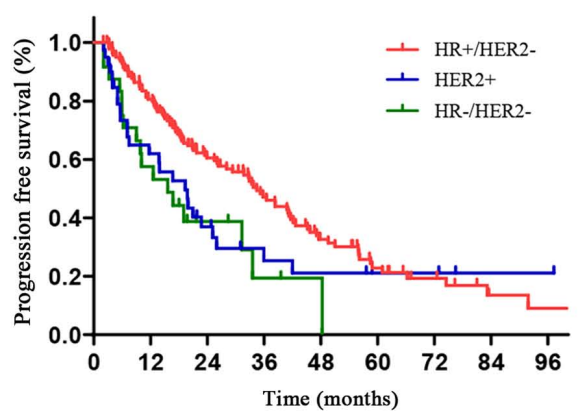

\begin{tabular}{|lccc|}
\hline & HR+/HER2- & HER2+ & HR-/HER2- \\
\hline Median PFS (months) & 34.5 & 19.4 & 15.6 \\
\hline Hazard Ratio & 1 & 1.51 & 2.16 \\
95\% CI & - & $0.92-2.14$ & $1.07-4.34$ \\
\hline Log-rank P-value & - & 0.002 & 0.002 \\
\hline
\end{tabular}

D

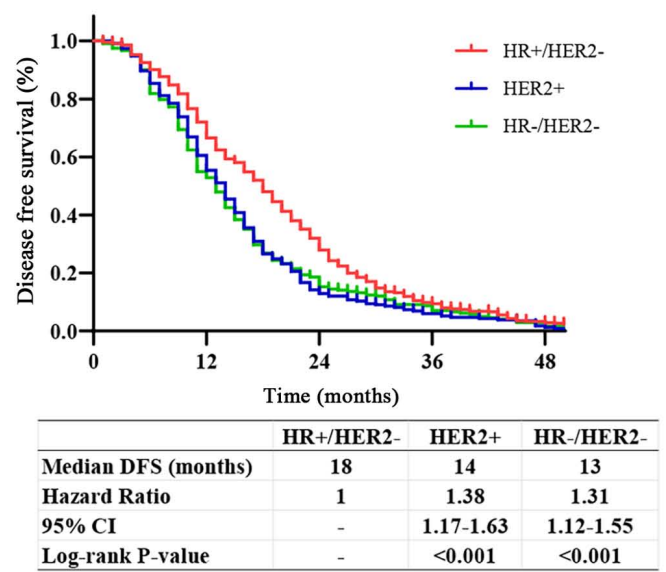

$\mathrm{F}$

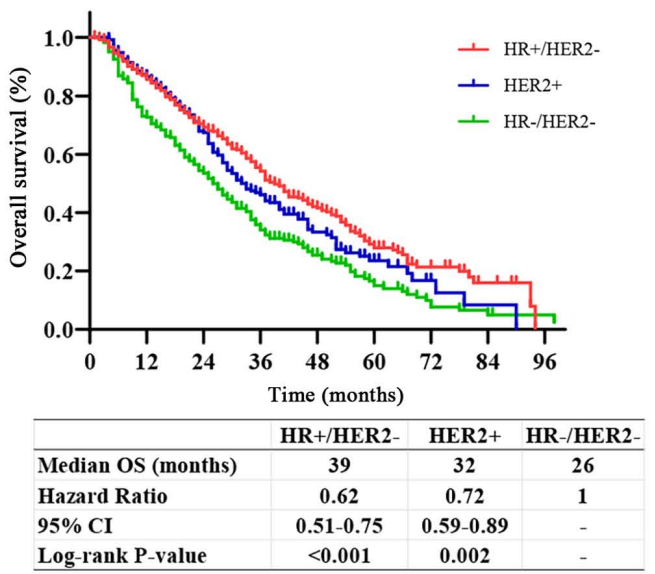

Figure 2. Kaplan-Meier survival curves stratified by molecular subtypes. (A) DFS, (B) PFS and (C) OS curves in BOM patients. (D) DFS, (E) PFS and (F) OS curves in non-BOM patients. DFS, disease-free survival; PFS, progression-free survival; OS, overall survival; BOM, bone-only metastasis; TNBC, triple-negative breast cancer; HER2, human epidermal growth factor receptor 2; HR, hormone receptor.

patients with liver metastasis were 76.8 and $16.1 \%$, respectively. The high-risk period of liver or lung metastasis was the first three years after diagnosis of bone metastasis and the high-risk period of brain metastasis was the first 2 years (Fig. 6).

\section{Discussion}

The present study was the largest real-world analysis comparing clinicopathological characteristics, survival and prognostic factors of patients with $\mathrm{BOM}$ and non-BOM MBC published to date, to the best of our knowledge, and may be of great significance for guiding clinical treatment and prediction of prognosis. Understanding the time and location of the second metastatic site may help guide the follow-up and reexamination of patients with BOM. The proportion of patients with clinical stage IV in the BOM group was significantly higher compared with that in the non-BOM group. A previous study indicated that the clinical stage was an independent risk 
Table VII. Characteristics at initial diagnosis of metastasis in patients with hormone receptor-positive/human epidermal growth factor receptor 2-negative bone-only metastasis.

\begin{tabular}{lccc}
\hline Characteristic & Chemotherapy, $\mathrm{n}(\%)$ & Endocrine therapy, $\mathrm{n}(\%)$ & Sequential therapy, $\mathrm{n}(\%)$ \\
\hline $\begin{array}{l}\text { Total patients } \\
\text { Age at metastasis diagnosis, years }\end{array}$ & $36(25)$ & $33(22.9)$ & $75(52.1)$ \\
$\quad<35$ & $3(8.3)$ & $6(18.2)$ & $0(0.0)$ \\
$35-60$ & $25(69.4)$ & $25(75.6)$ & $60(80.0)$ \\
$\geq 60$ & $8(22.2)$ & $2(6.1)$ & $15(20.0)$ \\
Location of bone metastasis & $0(0.0)$ & $2(5.7)$ & $2(3.4)$ \\
$\quad$ Axial & $29(80.9)$ & $25(80.0)$ & $59(79.3)$ \\
Appendicular & $7(19.1)$ & $6(14.3)$ & $14(17.2)$ \\
Axial and appendicular & & & $12(16.0)$ \\
Number of bone metastases & $8(22.2)$ & $21(63.6)$ & $63(84.0)$ \\
$\quad$ Single & $28(77.8)$ & $12(36.4)$ & \\
Multiple &
\end{tabular}

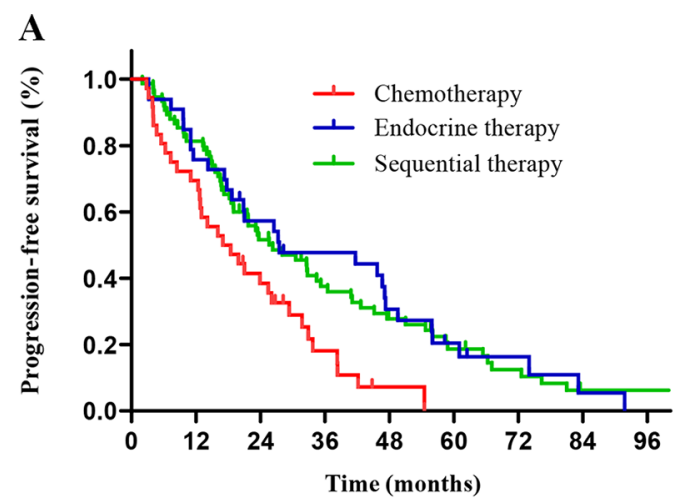

\begin{tabular}{|l|c|c|c|}
\hline & Chemotherapy & Endocrine therapy & Sequential therapy \\
\hline Median PFS (months) & 17.7 & 27.5 & 26.3 \\
\hline Hazard Ratio & 1 & 0.50 & 0.55 \\
\hline $95 \%$ CI & - & $0.29-0.85$ & $0.34-0.89$ \\
\hline Log-rank P-value & - & 0.003 & 0.004 \\
\hline
\end{tabular}

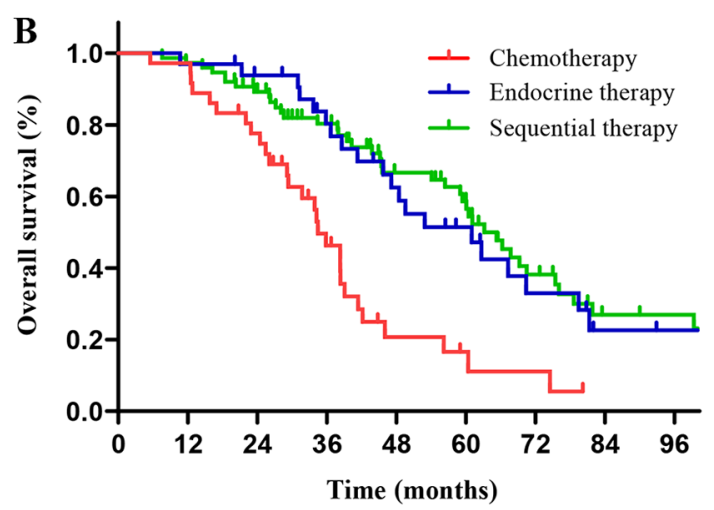

\begin{tabular}{l|c|c|c}
\hline & Chemotherapy & Endocrine therapy & Sequential therapy \\
\hline Median OS (months) & 34.5 & 61 & 63.2 \\
\hline Hazard Ratio & 1 & 0.49 & 0.36 \\
\hline $95 \%$ CI & - & $0.22-0.72$ & $0.20-0.65$ \\
\hline Log-rank P-value & - & $<0.001$ & $<0.001$ \\
\hline
\end{tabular}

Figure 3. Kaplan-Meier survival curves stratified by treatment methods in $\mathrm{HR}^{+}$BOM patients. (A) PFS and (B) OS curves stratified by treatment methods in $\mathrm{HR}^{+} \mathrm{BOM}$ patients. HR, hormone receptor; PFS, progression-free survival; OS, overall survival; BOM, bone-only metastasis.

factor for the incidence of bone metastasis in patients with breast cancer (25). The bone is the most common metastatic site of de novo MBC $(26,27)$. The 'seed-and-soil hypothesis' highlights the bone as the preferred site of metastatic development (28). In agreement with other studies $(13,29)$, the HR status and molecular subtypes were identified as important factors affecting the presence of $\mathrm{BOM}$. $\mathrm{HR}^{+}$status and in particular $\mathrm{HR}^{+} / \mathrm{HER} 2^{-}$(or luminal $\mathrm{A}$ ) carcinoma was more likely to develop BOM $(11,12,29-31)$. Patients with HER2 ${ }^{+}$or $\mathrm{HR}^{-} / \mathrm{HER} 2^{-}$carcinoma were more likely to develop visceral and cerebral metastases, which was similar to the results of earlier studies (31-35).

Prior studies indicated that the prognosis of patients with BOM was better compared with that of breast cancer patients with visceral or brain metastasis (36-38). The results of the present study were in agreement with this, as the DFS, PFS and OS of patients with BOM were significantly longer compared with those of patients with non-BOM. Patients with non-BOM had metastases, which were highly invasive and more prone to progression. Recent studies have reported median OS times of patients with BOM of 51-59 months $(7,15,16)$, which was longer than the median OS time of the cohort of the present study. A reason for this difference may be that patients in developed countries have comparatively better access to healthcare and receive increased medical attention, which may prevent recurrence or metastasis. To a certain extent, Chinese patients have limited access to the latest drugs and high medical costs skew comparisons between cohorts from different countries.

In the present study, $\mathrm{HR}^{+}$primary tumors were significantly and independently associated with improved prognosis for patients with BOM, in agreement with previous studies $(15,16,39)$. The ER status was closely associated with the histological grade; highly differentiated tumors tended to have higher expression levels of ER (40), which may be due to improved prognosis of $\mathrm{ER}^{+}$patients. The number and the 


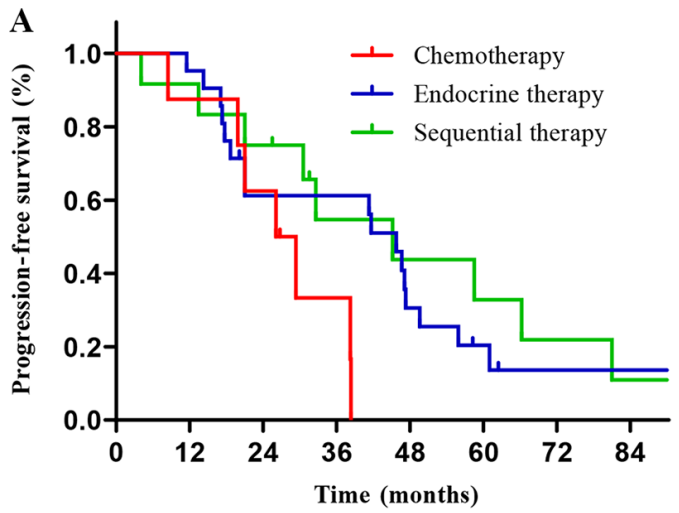

\begin{tabular}{l|c|c|c|}
\hline & Chemotherapy & Endocrine therapy & Sequential therapy \\
\hline Median PFS (months) & 21 & 37.1 & 39.4 \\
\hline Hazard Ratio & 1 & 0.42 & 0.29 \\
\hline $95 \%$ CI & - & $0.19-0.96$ & $0.12-0.72$ \\
\hline Log-rank P-value & - & 0.03 & 0.04 \\
\hline
\end{tabular}

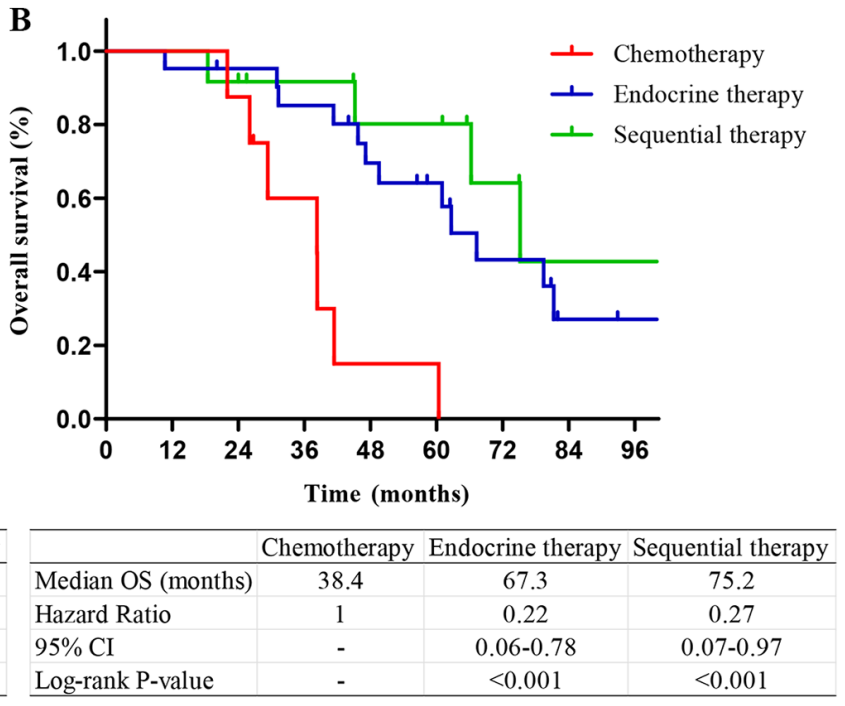

Figure 4. Kaplan-Meier survival curves stratified by treatment methods in patients with a single bone metastasis. (A) PFS and (B) OS curves in bone-only metastasis patients with a single bone metastasis. PFS, progression-free survival; OS, overall survival.

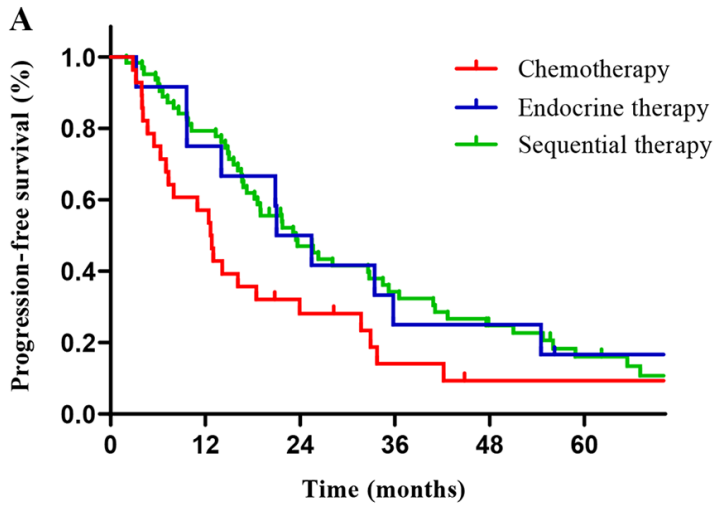

\begin{tabular}{l|c|c|c}
\hline & Chemotherapy & Endocrine therapy & Sequential therapy \\
\hline Median PFS (months) & 12.7 & 18.5 & 21.7 \\
\hline Hazard Ratio & 1 & 0.56 & 0.58 \\
\hline $95 \%$ CI & - & $0.31-0.92$ & $0.36-0.94$ \\
\hline Log-rank P-value & - & 0.03 & 0.01 \\
\hline
\end{tabular}

B

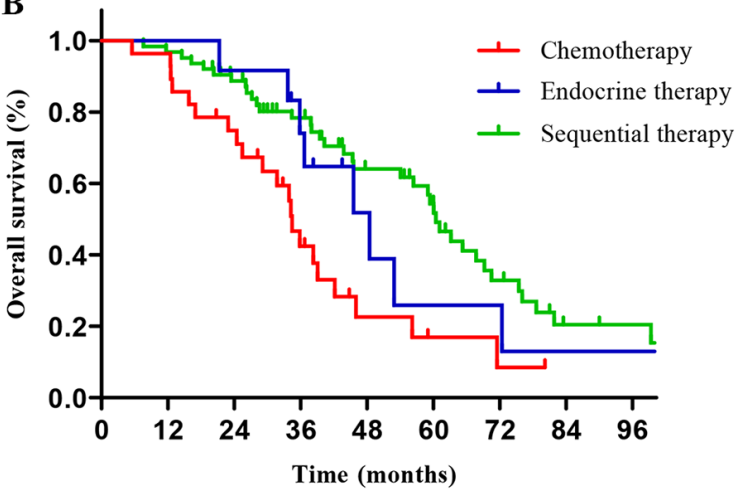

\begin{tabular}{l|ccc|}
\hline & \multicolumn{4}{c}{ Chemotherapy } & Endocrine therapy & Sequential therapy \\
\hline Median OS(months) & 34.5 & 47.8 & 59.4 \\
\hline Hazard Ratio & 1 & 0.49 & 0.53 \\
\hline $95 \%$ CI & - & $0.25-0.95$ & $0.30-0.93$ \\
\hline Log-rank P-value & - & 0.02 & 0.004 \\
\hline
\end{tabular}

Figure 5. Kaplan-Meier survival curves stratified by treatment methods in patients with multiple bone metastases. (A) PFS and (B) OS curves in BOM patients with multiple bone metastases. PFS, progression-free survival; OS, overall survival; BOM, bone-only metastases.

location of bone metastases were independent prognostic factors affecting PFS and OS of patients with BOM in the present study. These results were similar to those of previous studies $(15,41,42)$, in terms of multiple bone metastases, as well as combined axial and appendicular bone metastases being associated with unfavorable prognosis of patients with BOM. The location of bone metastasis had no impact on the incidence of SREs in this study. Patients with combined appendicular and axial metastases at BOM diagnosis had a significantly greater odds of experiencing bone pain compared with patients with metastases confined to axial locations (42), decreasing the quality of life of patients. The present study suggested that patients with appendicular bone metastasis had improved prognosis. Specifically, there were only 7 patients with BOM with appendicular bone metastasis alone, all of which were a solitary bone metastasis at the time-point of BOM diagnosis, and 3 patients received sequential therapy and 2 patients received endocrine therapy. It is probably due to the small number of patients with appendicular bone metastasis and the superior treatment received that these patients had a longer survival time. Another previous retrospective study on 91 patients with bone metastases suggested that bisphosphonates significantly prolonged OS of patients with breast cancer (39). However, bisphosphonates therapy was not associated with PFS or OS in patients with BOM in the present study. There may have been a selection bias in the previous study, as patients in good physical condition or those expected to survive for longer were more likely to receive bisphosphonates. In patients with $\mathrm{MBC}$, bisphosphonates are able to prevent or delay SREs, but cannot prolong OS (18,43-45). To clarify, denosumab had not been marketed in the Chinese mainland by the end of the present study, and thus, none of the patients in the present study were treated with denosumab for bone preservation. 
Table VIII. Associations between SREs and characteristics of bone metastasis.

\begin{tabular}{|c|c|c|c|c|c|}
\hline \multirow[b]{2}{*}{ Characteristic } & \multicolumn{2}{|c|}{ SREs } & \multirow[b]{2}{*}{ Total, $\mathrm{n}$} & \multirow[b]{2}{*}{$\chi^{2}$} & \multirow[b]{2}{*}{ P-value } \\
\hline & Yes, n (\%) & No, n $(\%)$ & & & \\
\hline Number of bone metastasis & & & & 28.316 & $<0.001$ \\
\hline Single & $21(16)$ & 39 (50.6) & 60 & & \\
\hline Multiple & $110(84)$ & $38(49.4)$ & 148 & & \\
\hline Location of bone metastasis & & & & 0.314 & 0.855 \\
\hline Appendicular & $5 \quad(3.8)$ & $2(2.6)$ & 7 & & \\
\hline Axial & $102(77.9)$ & $62(80.5)$ & 164 & & \\
\hline Appendicular and axial & $24(18.3)$ & 13 (16.9) & 37 & & \\
\hline $\mathrm{HR}^{+} / \mathrm{HER} 2-\mathrm{BOM}$ treatment & & & & 0.013 & 0.990 \\
\hline Chemotherapy & $22(25.3)$ & $14(24.6)$ & 36 & & \\
\hline Endocrine therapy & $20(23)$ & $13(22.8)$ & 33 & & \\
\hline Sequential therapy & $45(51.7)$ & $30(52.6)$ & 75 & & \\
\hline
\end{tabular}

SREs, skeletal-related events; BOM, bone-only metastasis; HR, hormone receptor; HER2, human epidermal growth factor receptor 2.

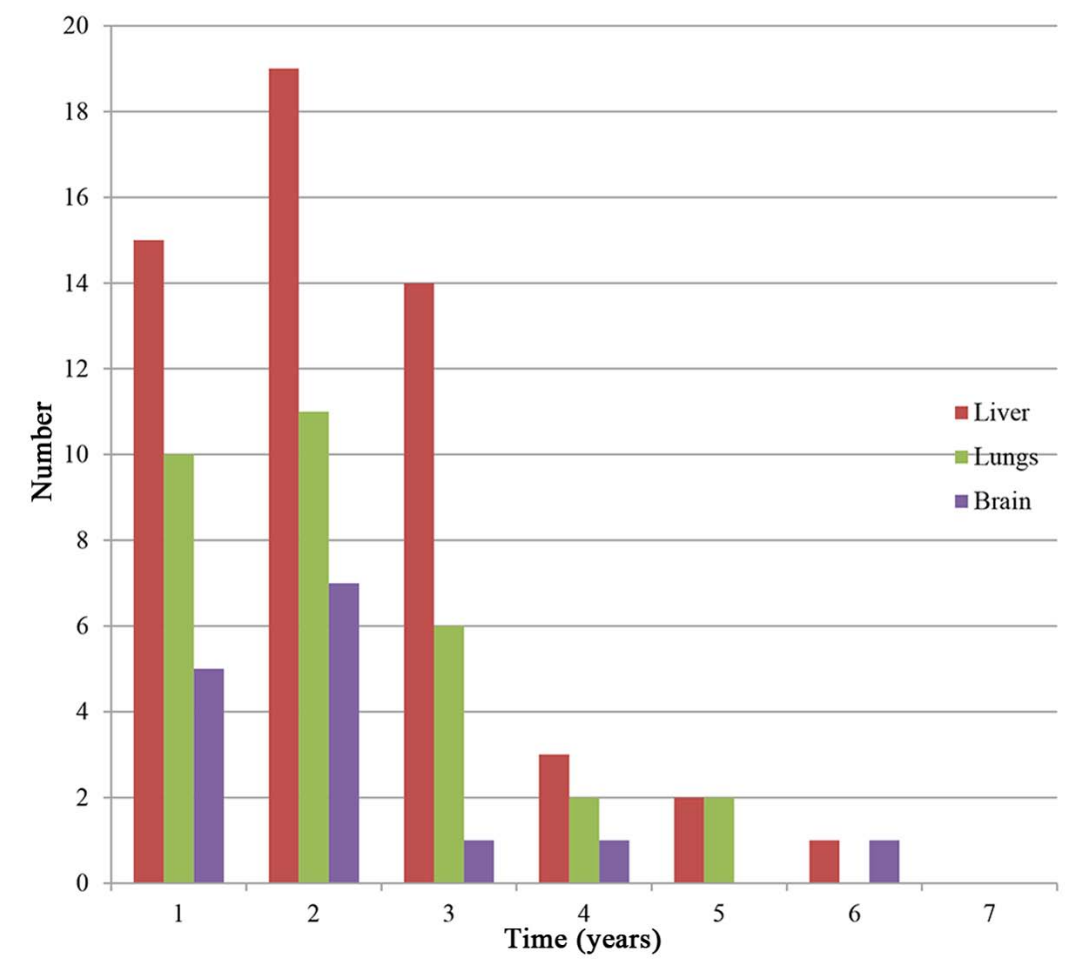

Figure 6. Distribution of the secondary new metastatic lesion sites in patients after bone-only metastasis diagnosis. The liver, lungs and the brain were the major organs involved. The numbers are decreasing with time because only newly diagnosed metastases are shown and some patients were dying.

Non-BOM patients aged $\leq 35$ years at diagnosis of metastasis exhibited poorer prognosis compared with patients aged $>35$ years. This may have been due to the carcinomas in younger patients being more invasive and aggressive. It remains elusive whether age at primary diagnosis influences outcomes. Purushotham et al (46) indicated a decrease in the risk of distant metastasis with increasing age. Hung et al (47) determined that patients aged $<35$ years had a significantly higher risk of brain metastasis. Chen et al (38) suggested that older age significantly contributed to poor prognosis.
In the present study, there were no associations between age at primary diagnosis and prognosis of patients with breast cancer. Patients with $\mathrm{HR}^{-}$status had a particularly high risk and poor prognosis, similar to previous studies (48-50). Laohavinij et al (51) indicated that T4 was significantly associated with poor prognosis of patients with $\mathrm{MBC}$. In patients of the present study with non-BOM, T3-4 vs. T1-2 carcinoma was associated with poor prognosis.

In the present study, the DFS of both patients with BOM and non-BOM with $\mathrm{HR}^{+} / \mathrm{HER} 2^{-}$status was significantly 
longer, which was similar to previous studies $(7,33)$. In a previous study, the median follow-up time was 80.8 months and the luminal A subtype had the highest 10-year DFS rate compared with luminal B, luminal/HER2, HER2 enriched and TNBC (52). In agreement with earlier studies $(7,29)$, patients of the present study with BOM and $\mathrm{HR}^{+} / \mathrm{HER} 2^{-}$had improved PFS and OS compared with patients with HER2 ${ }^{+}$ or HR $/ \mathrm{HER} 2$ - A previous large retrospective study indicated that the luminal A subtype had the highest 10-year survival rate, followed by luminal $\mathrm{B}$ and luminal/HER2, while HER2 enriched and TNBC had the worst survival (52), which was similar to the results of the present study. Amongst the patients with non-BOM in the present study, the PFS and OS of the $\mathrm{HR}^{+} / \mathrm{HER} 2^{-}$and HER2 ${ }^{+}$types was superior to that of HR/HER $2^{-}$cases. Patients with HER2 ${ }^{+}$breast cancer had relatively improved survival. Studies suggested that among patients with MBC, those with HER $2^{+}$tumors had the best prognostic outcomes, while those with HR/HER2- tumors had the worst prognosis $(12,53)$, possibly due to advances in anti-HER2 molecular targeted drugs.

A previous study indicated that the survival rate of patients with $\mathrm{BOM}$ of the $\mathrm{HR}^{+} / \mathrm{HER} 2^{-}$type treated with sequential therapy was significantly higher compared with those treated with chemotherapy or endocrine therapy alone (16). However, these results are different from those of the present study, according to which patients receiving endocrine or sequential therapy had longer PFS and OS times compared with patients receiving chemotherapy; however, there was no significant difference between outcomes of endocrine therapy and sequential therapy. The same results were obtained in subgroups of patients with a single bone metastasis or multiple bone metastases. As Chinese patients have limitations regarding the availability of the latest drugs and affordability of medical treatments, palbociclib was approved by the Chinese Food and Drug Administration on July 31, 2018 (24). There were only 3 patients receiving cyclin-dependent kinase $4 / 6$ inhibitors (palbociclib) in the endocrine therapy group. In the present study, the impact of the time of diagnosis was not considered. Among the patients with BOM, only a small number received fulvestrant and palbociclib as the first-line endocrine therapy. Of note, certain patients with BOM may benefit from the rapid development of endocrine drugs in the future. Furthermore, the present study indicated that the number of bone metastases should be considered by the clinician when making a decision on treatment options. Due to limited availability of drugs, as well as the intense demand for relieving symptoms, several patients with multiple bone metastases prefer sequential therapy. However, in the present study, endocrine therapy alone was as effective as sequential therapy, and sequential therapy may result in more adverse reactions, including vomiting, leukopenia and alopecia. Therefore, endocrine therapy may be preferred for patients with $\mathrm{HR}^{+} / \mathrm{HER} 2^{-}$BOM.

Earlier studies suggested that major risk factors for SREs were age, menopausal status, clinical stage, tissue grade and molecular subtypes $(54,55)$. The number of bone metastases was significantly associated with SREs in the present study. The incidence of SREs in patients with multiple bone metastases was significantly higher compared with that in patients with a single bone metastasis. Kuchuk et al (55) indicated that patients with $\geq 5$ bone metastases were more likely to have an SRE than those with $<5$. Parkes et al (42) determined that multiple bone metastases were associated with increased pain.

Among the patients of the present study with BOM who developed secondary site metastases, the liver was the most common site, followed by the lung and the brain. According to previous studies, the liver was the most frequent organ of metastasis after bone metastasis in $\mathrm{HR}^{+}$breast cancer patients $(11,56)$. Furthermore, patients with HER2 ${ }^{+}$tumors were more prone to liver metastasis $(32,57)$. In the present study, the majority of patients with liver metastasis were of the $\mathrm{HR}^{+}$or HER $2^{+}$types. Thus, it is necessary to pay increasing attention to the possibility of liver and lung metastasis in the first three years after diagnosis, and to brain metastases in the first two years after diagnosis to detect metastasis as early as possible.

The present study had certain limitations. The cohort was based on patients from a single institution and may thus have different characteristics from those at other centers, limiting widespread generalizations. The present study was a retrospective study and there may have been selection bias. The systemic therapy included various drugs, doses and courses, and future studies using randomization designs for different treatment methods are required.

In conclusion, the prognosis of patients with BOM was better compared with that of non-BOM patients. HR- tumors, chemotherapy alone, multiple bone metastases, and combined axial and appendicular bone metastases, were significantly associated with poor prognosis in patients with BOM. An age at metastasis or recurrence of $\leq 35$ years, $\mathrm{HR}^{-}$status and a tumor stage of T3-4 were significantly associated with a poorer prognosis of patients with non-BOM. For patients with $\mathrm{BOM}$ and $\mathrm{HR}^{+} / \mathrm{HER} 2^{-}$status, endocrine therapy alone achieved satisfactory results.

\section{Acknowledgements}

Not applicable.

\section{Funding}

The present study was supported by grants from the National Natural Science Foundation of China (grant nos. 81702636 and 81602340), the Anticancer Key Technologies R\&D Program of Tianjin (grant no. 12ZCDZSY16200), the Natural Science Foundation of Tianjin (grant no. 18JCYBJC93500) and the Science \& Technology Development Fund of Tianjin Education Commission for Higher Education (grant no. 2016YD15).

\section{Availability of data and materials}

The datasets used and/or analyzed during the present study are available from the corresponding author on reasonable request.

\section{Authors' contributions}

LZ, JZ, ZL, YW and ZT conceived and designed the study. $\mathrm{ZT}$ provided administrative support and gave final approval of the version to be published. JZ, ZL, YW and LZ collected, 
analyzed and interpreted the data. JZ and LZ drafted and revised the manuscript. All authors read and approved the final manuscript.

\section{Ethics approval and consent to participate}

The present study was approved by the Institutional Review Committee and requirement of informed consent was waived due to the retrospective study design. The present study was performed in accordance with all relevant guidelines and procedures and approved by the Tianjin Medical University Ethical Committee (Tianjin, China).

\section{Patient consent for publication}

Not applicable.

\section{Competing interests}

The authors declare that they have no competing interests.

\section{References}

1. Schröder J, Fietz T, Köhler A, Petersen V, Tesch H, Spring L, Fleitz A, Jänicke M and Marschner N; TMK-Group (Tumour Registry Breast Cancer): Treatment and pattern of bone metastases in 1094 patients with advanced breast cancer-Results from the prospective German Tumour Registry Breast Cancer cohort study. Eur J Cancer 79: 139-148, 2017.

2. Jin $X$ and Mu P: Targeting breast cancer metastasis. Breast Cancer (Auckl) 9 (Suppl 1): S23-S34, 2015.

3. Early Breast Cancer Trialists' Collaborative Group (EBCTCG: Effects of chemotherapy and hormonal therapy for early breast cancer on recurrence and 15-year survival: An overview of the randomised trials. Lancet 365: 1687-717, 2005.

4. Manders K, van de Poll-Franse LV, Creemers GJ, Vreugdenhil G, van der Sangen MJ, Nieuwenhuijzen GA, Roumen RM and Voogd AC: Clinical management of women with metastatic breast cancer: A descriptive study according to age group. BMC Cancer 6: 179, 2006.

5. Mulcrone PL, Campbell JP, Clément-Demange L, Anbinder AL, Merkel AR, Brekken RA, Sterling JA and Elefteriou F: Skeletal colonization by breast cancer cells is stimulated by an osteoblast and $32 \mathrm{AR}-\mathrm{dependent} \mathrm{Neo-angiogenic} \mathrm{switch.} \mathrm{J} \mathrm{Bone} \mathrm{Miner}$ Res 32: 1442-1454, 2017.

6. Coleman RE and Rubens RD: The clinical course of bone metastases from breast cancer. Br J Cancer 55: 61-66, 1987.

7. Parkes A, Clifton K, Al-Awadhi A, Oke O, Warneke CL, Litton JK and Hortobagyi GN: Characterization of bone only metastasis patients with respect to tumor subtypes. NPJ Breast Cancer 4: 2, 2018

8. von Moos R, Body JJ, Egerdie B, Stopeck A, Brown J, Fallowfield L, Patrick DL, Cleeland C, Damyanov D, Palazzo FS, et al: Pain and analgesic use associated with skeletal-related events in patients with advanced cancer and bone metastases. Support Care Cancer 24: 1327-1337, 2016.

9. Sathiakumar N, Delzell E, Morrisey MA, Falkson C, Yong M, Chia V, Blackburn J, Arora T, Brill I and Kilgore ML: Mortality following bone metastasis and skeletal-related events among women with breast cancer: A population-based analysis of U.S. Medicare beneficiaries, 1999-2006. Breast Cancer Res Treat 131: 231-238, 2012.

10. Li BT, Wong MH and Pavlakis N: Treatment and prevention of bone metastases from breast cancer: A comprehensive review of evidence for clinical practice. J Clin Med 3: 1-24, 2014.

11. Molnár IA, Molnár BÁ, Vízkeleti L, Fekete K, Tamás J, Deák P, Szundi C, Székely B, Moldvay J, Vári-Kakas S, et al: Breast carcinoma subtypes show different patterns of metastatic behavior. Virchows Arch 470: 275-283, 2017.

12. Gong Y, Liu YR, Ji P, Hu X and Shao ZM: Impact of molecular subtypes on metastatic breast cancer patients: A SEER population-based study. Sci Rep 7: 45411, 2017.
13. Solomayer EF, Diel IJ, Meyberg GC, Gollan C and Bastert G: Metastatic breast cancer: Clinical course, prognosis and therapy related to the first site of metastasis. Breast Cancer Res Treat 59: 271-278, 2000.

14. Plunkett TA, Smith P and Rubens RD: Risk of complications from bone metastases in breast cancer. Implications for management. Eur J Cancer 36: 476-82, 2000.

15. Ahn SG, Lee HM, Cho SH, Lee SA, Hwang SH, Jeong J and Lee HD: Prognostic factors for patients with bone-only metastasis in breast cancer. Yonsei Med J 54: 1168-1177, 2013.

16. Niikura N, Liu J, Hayashi N, Palla SL, Tokuda Y, Hortobagyi GN, Ueno NT and Theriault RL: Treatment outcome and prognostic factors for patients with bone-only metastases of breast cancer: A single-institution retrospective analysis. Oncologist 16: 155-164, 2011.

17. Eckhardt BL, Francis PA, Parker BS and Anderson RL: Strategies for the discovery and development of therapies for metastatic breast cancer. Nat Rev Drug Discov 11: 479-497, 2012.

18. Erdogan B and Cicin I: Medical treatment of breast cancer bone metastasis: From bisphosphonates to targeted drugs. Asian Pac J Cancer Prev 15: 1503-1510, 2014.

19. Sze WM, Shelley M, Held I and Mason M: Palliation of metastatic bone pain: Single fraction versus multifraction radiotherapy-a systematic review of the randomised trials. Cochrane Database Syst Rev 2002: CD004721, 2004.

20. Hammond ME, Hayes DF, Dowsett M, Allred DC, Hagerty KL, Badve S, Fitzgibbons PL, Francis G, Goldstein NS, Hayes M, et al: American Society of Clinical Oncology/College of American Pathologists guideline recommendations for immunohistochemical testing of estrogen and progesterone receptors in breast cancer. J Clin Oncol 28: 2784-2795, 2010.

21. Qian XL, Wen HY, Yang YL, Gu F, Guo XJ, Liu FF, Zhang L, Zhang XM and Fu L: Assessment of dual-probe Her-2 fluorescent in situ hybridization in breast cancer by the 2013 ASCO/CAP guidelines produces more equivocal results than that by the 2007 ASCO/CAP guidelines. Breast Cancer Res Treat 159: 31-39, 2016.

22. Tiedemann K, Hussein O and Komarova SV: Role of altered metabolic microenvironment in osteolytic metastasis. Front Cell Dev Biol 8: 435, 2020.

23. Xiong X, Zhang Z, Ren J, Zhang J, Pan X, Zhang L, Gong S and Jin S: Impact of universal medical insurance system on the accessibility of medical service supply and affordability of patients in China. PLoS One 13: e0193273, 2018.

24. Hu X, Li T, Wang B, Zhang J, Yu X and Shao Z: Comparison of 4th ESO-ESMO international consensus guidelines for advance breast cancer and Chinese anti-cancer association committee of Breast Cancer Society guideline. Breast 45: 36-42, 2019.

25. Yamashiro H, Takada M, Nakatani E, Imai S, Yamauchi A, Tsuyuki S, Matsutani Y, Sakata S, Wada Y, Okamura R, et al: Prevalence and risk factors of bone metastasis and skeletal related events in patients with primary breast cancer in Japan. Int J Clin Oncol 19: 852-862, 2014.

26. Hölzel D, Eckel R, Bauerfeind I, Baier B, Beck T, Braun M, Ettl J, Hamann U, Harbeck N, Kiechle M, et al: Survival of de novo stage IV breast cancer patients over three decades. J Cancer Res Clin Oncol 143: 509-519, 2017.

27. Miao H, Hartman M, Bhoo-Pathy N, Lee SC, Taib NA, Tan EY, Chan P, Moons KG, Wong HS, Goh J, et al: Predicting survival of de novo metastatic breast cancer in Asian women: Systematic review and validation study. PLoS One 9: e93755, 2014.

28. Roodman GD: Mechanisms of bone metastasis. N Engl J Med 350: 1655-1664, 2004.

29. Diessner J, Wischnewsky M, Stüber T, Stein R, Krockenberger M, Häusler S, Janni W, Kreienberg R, Blettner M, Schwentner L, et al: Evaluation of clinical parameters influencing the development of bone metastasis in breast cancer. BMC Cancer 16: 307, 2016.

30. Zhang H, Zhu W, Biskup E, Yang W, Yang Z, Wang H, Qiu X, Zhang $\mathrm{C}, \mathrm{Hu} \mathrm{G}$ and $\mathrm{Hu} \mathrm{G}$ : Incidence, risk factors and prognostic characteristics of bone metastases and skeletal-related events (SREs) in breast cancer patients: A systematic review of the real world data. J Bone Oncol 11: 38-50, 2018.

31. Park HS, Kim S, Kim K, Yoo H, Chae BJ, Bae JS, Song BJ and Jung SS: Pattern of distant recurrence according to the molecular subtypes in Korean women with breast cancer. World J Surg Oncol 10: 4, 2012.

32. Leone BA, Vallejo CT, Romero AO, Machiavelli MR, Pérez JE, Leone J and Leone JP: Prognostic impact of metastatic pattern in stage IV breast cancer at initial diagnosis. Breast Cancer Res Treat 161: 537-548, 2017. 
33. Metzger-Filho O, Sun Z, Viale G, Price KN, Crivellari D, Snyder RD, Gelber RD, Castiglione-Gertsch M, Coates AS, Goldhirsch A and Cardoso F: Patterns of Recurrence and outcome according to breast cancer subtypes in lymph node-negative disease: Results from international breast cancer study group trials VIII and IX. J Clin Oncol 31: 3083-3090, 2013.

34. Soni A, Ren Z, Hameed O, Chanda D, Morgan CJ, Siegal GP and Wei S: Breast cancer subtypes predispose the site of distant metastases. Am J Clin Pathol 143: 471-478, 2015.

35. Beca F, Santos R, Vieira D, Zeferino L, Dufloth R and Schmitt F: Primary relapse site pattern in women with triple-negative breast cancer. Pathol Res Pract 210: 571-575, 2014.

36. Domchek SM, Younger J, Finkelstein DM and Seiden MV: Predictors of skeletal complications in patients with metastatic breast carcinoma. Cancer 89: 363-368, 2000

37. Lipton A: Should bisphosphonates be utilized in the adjuvant setting for breast cancer. Breast Cancer Res Treat 122: 627-636, 2010.

38. Chen MT, Sun HF, Zhao Y, Fu WY, Yang LP, Gao SP, Li LD, Jiang HL and Jin W: Comparison of patterns and prognosis among distant metastatic breast cancer patients by age groups: A SEER population-based analysis. Sci Rep 7: 9254, 2017.

39. James JJ, Evans AJ, Pinder SE, Gutteridge E, Cheung KL, Chan S and Robertson JF: Bone metastases from breast carcinoma: Histopathological-radiological correlations and prognostic features. Br J Cancer 89: 660-655, 2003.

40. Williams MR, Todd JH, Ellis IO, Dowle CS, Haybittle JL, Elston CW, Nicholson RI, Griffiths K and Blamey RW: Oestrogen receptors in primary and advanced breast cancer: An eight year review of 704 cases. Br J Cancer 55: 67-73, 1987.

41. Koizumi M, Yoshimoto M, Kasumi F and Ogata E: Comparison between solitary and multiple skeletal metastatic lesions of breast cancer patients. Ann Oncol 14: 1234-1240, 2003.

42. Parkes A, Warneke CL, Clifton K, Al-Awadhi A, Oke O, Pestana RC, Alhalabi O, Litton JK and Hortobagyi GN: Prognostic factors in patients with metastatic breast cancer with bone-only metastases. Oncologist 23: 1282-1288, 2018.

43. Henry DH, Costa L, Goldwasser F, Hirsh V, Hungria V, Prausova J, Scagliotti GV, Sleeboom H, Spencer A, Vadhan-Raj S, et al: Randomized, double-blind study of denosumab versus zoledronic acid in the treatment of bone metastases in patients with advanced cancer (excluding breast and prostate cancer) or multiple myeloma. J Clin Oncol 29: 1125-1132, 2011.

44. Coleman RE: Impact of Bone-targeted treatments on skeletal morbidity and survival in breast cancer. Oncology (Williston Park) 30: 695-702, 2016.

45. Biskup E, Cai F and Vetter M: Bone targeted therapies in advanced breast cancer. Swiss Med Wkly 147: W14440, 2017.
46. Purushotham A, Shamil E, Cariati M, Agbaje O, Muhidin A, Gillett C, Mera A, Sivanadiyan K, Harries M, Sullivan R, et al: Age at diagnosis and distant metastasis in breast cancer-a surprising inverse relationship. Eur J Cancer 50: 1697-1705, 2014.

47. Hung MH, Liu CY, Shiau CY, Hsu CY, Tsai YF, Wang YL, Tai LC, King KL, Chao TC, Chiu JH, et al: Effect of age and biological subtype on the risk and timing of brain metastasis in breast cancer patients. PLoS One 9: e89389, 2014.

48. Ren Z, Li Y, Hameed O, Siegal GP and Wei S: Prognostic factors in patients with metastatic breast cancer at the time of diagnosis. Pathol Res Pract 210: 301-306, 2014.

49. Jung SY, Rosenzweig M, Sereika SM, Linkov F, Brufsky A and Weissfeld JL: Factors associated with mortality after breast cancer metastasis. Cancer Causes Control 23: 103-112, 2012.

50. Cossetti RJ, Tyldesley SK, Speers CH, Zheng Y and Gelmon KA: Comparison of breast cancer recurrence and outcome patterns between patients treated from 1986 to 1992 and from 2004 to 2008. J Clin Oncol 33: 65-73, 2015.

51. Laohavinij S, Paul V and Maneenil K: Survival and prognostic factors of metastatic breast cancer. J Med Assoc Thai 100 (Suppl 1): S16-S26, 2017.

52. Ignatov A, Eggemann H, Burger E and Ignatov T: Patterns of breast cancer relapse in accordance to biological subtype. J Cancer Res Clin Oncol 144: 1347-1355, 2018.

53. Press DJ, Miller ME, Liederbach E, Yao K and Huo D: De novo metastasis in breast cancer: Occurrence and overall survival stratified by molecular subtype. Clin Exp Metastasis 34: 457-465, 2017.

54. Yamashiro H, Takada M, Nakatani E, Imai S, Yamauchi A, Tsuyuki S, Matsutani Y, Sakata S, Wada Y, Okamura R, et al: Prevalence and risk factors of bone metastasis and skeletal related events in patients with primary breast cancer in Japan. Int J Clin Oncol 19: 852-862, 2014

55. Kuchuk I, Hutton B, Moretto P, Ng T, Addison CL and Clemons $\mathrm{M}$ : Incidence, consequences and treatment of bone metastases in breast cancer patients-Experience from a single cancer Centre. J Bone Oncol 2: 137-144, 2013.

56. Ma R, Feng Y, Lin S, Chen J, Lin H, Liang X, Zheng H and Cai X: Mechanisms involved in breast cancer liver metastasis. J Transl Med 13: 64, 2015.

57. Wei S and Siegal GP: Metastatic organotropism: An intrinsic property of breast cancer molecular subtypes. Adv Anat Pathol 24: 78-81, 2017.

This work is licensed under a Creative Commons Attribution-NonCommercial-NoDerivatives 4.0 International (CC BY-NC-ND 4.0) License. 